\title{
Motor Recovery of Lower Limbs in Cerebral Palsy with Botulinum Toxin and Physioteraphy
}

\author{
Mastromauro L*, Romanelli E, Marvulli RG and G Ianieri \\ U.O.C. Physical end Rheabilitation Medicine and Spinal Cord Unit, University of Study of Bari Aldo Moro, Italy
}

Submission: March 26, 2017; Published: April 18, 2017

*Corresponding author: Lucia Mastromauro, U.O.C. Physical end Rheabilitation Medicine and Spinal Cord Unit, University of Study of Bari Aldo Moro, via C. Alberto n9 Sammichele di Bari (BA), Tel: 3208535155; Email: lucia.mastromauro@libero.it

\begin{abstract}
Introduction: The gait is a central function in the neuropsychological development of the normal child and in neuromotor diseases such as PCI. Spasticity is a major problem that prevents the development of motor functions remaining in these patients, thus producing a limited participation in recreational and sports activities and social activities. The synergistic action of the FET and the BTX-A can be a valuable aid, as the transient inhibition of muscle spasticity, can allow the subject to learn to reorganize through the rehabilitation intervention movement in a different way, in order to reduce the functional limitations in the lower limbs allowing a greater motor skills and thus a better quality of life.
\end{abstract}

Material and methods: 2 groups of 15 patients (PCI form paraparetic) mean age $9.3 \pm 3.2$ years. Patients at recruiting visit (T0) had spastic hypertonia borne muscles of the lower limbs with a tendency to be crossed scissor gait and foot equinus. All patients were evaluated with the MAS scale, WeeFim and evaluation miometrica muscle AM, GM and GL; Group 1 was treated with botulinum toxin type A Xeomin ${ }^{\circledR}$ in muscles AM, GM, GL and soleus and subsequent FKT other day, group 2 instead performed only FKT to three times a week. At each visit (T0=injection, T1=1 month, 3 months=T2, T3=4 months, T4=5 months, T5 inj. $=6$ months, T6=7 months, $\mathrm{t} 7=9$ months, $\mathrm{T} 8=10$ months, $\mathrm{T} 9=11$ months, T10 inj. $=12$ months), all patients were evaluated with indicated scales.

Result: All the assessments of the MAS, the WeeFim and myometric measurement have shown that the effect of the toxin affects positively on spasticity and motor skills of patients, resulting in a greater postural stability and an improvement in gait paretic spastic, reducing equinus foot, knee flexion and adduction of the thighs, thus improving the range of motion and finally the limb deformities.

Conclusion: The combined action of BTX-A and FKT evaluated with stairs MAS and WeeFim and with the objective measurement of myometric tone showed that these patients after treatment are able to use compartments engines in a more functional and above all intentional, consistent with its willingness to perform a particular action, thus ensuring greater integration opportunities in classroom-recreational-sports with greater social integration and thus better quality of life.

\section{Introduction}

The Cerebral Palsy is pathological form of developmental age that can be defined as a "Persistent disorder but not immutable posture and movement, due to an alteration of organic and nonprogressive brain function, for reasons pre, or for post-natal, before the complete the growth and development" (Spastic Society, Berlin 1996) [1-3]. Therefore, it is a serious disease both in terms of clinical complications and for the social and human implications, there is often a whole host of physical, sensitive, intellectual and psychological abnormalities, individually or in combination with each other. Early recognition and treatment rehabilitation properly planned and implemented, requiring a multidisciplinary collaboration, a harmonious team work, performed with unity of purpose, commitment and continuity. In recent years, the possibilities of drug treatment and rehabilitation for children with cerebral palsy have increased, especially with regard to spasticity, with the common goal to positively influence the quality of life of children [4]. To achieve this objective we try to quantify, through the drafting of functional and motor rating scales, the relationship between disability and its impact on the child's life and its capacity for autonomy, as the only clinical parameters (range of motion, spasticity, dystonia ) do not inform in a precise way the actual and significant improvement of the quality of life of the child following treatment. The aim of this work is to demonstrate the effectiveness of combination therapy among botulinum toxin, and a physiotherapy, in the motor recovery of lower limbs, resulting in improved living conditions in individuals with cerebral palsy. The reduction spastic hypertonia allows small patients to be more efficient on the functional level and thus achieve, compatibly with the lesions of the base, a certain degree of autonomy. 


\section{Material and Methods}

Were selected 30 patients, 15 females and 15 males, suffering from spastic paraparesis outcome of cerebral palsy. The average age of the patients was $9.3 \pm 3.2$ years. We have chose two groups: in the group A the patients were treated with botulinum toxin Xeomin ${ }^{\circledR}$ and physioterapy; in the group B the childs performed only physioterapy. We became interested in spastic hypertonia, that affected the muscles of the lower limbs, resulting in joint spoiled attitudes and, in some cases, joint fixity no functional. The patients had a postural attitude often altered by half decline of the knees, adduction and internal rotation of the thighs with a tendency, in attempts to walking, to intersect lower limbs like scissors, feet in equinus varus. In addition, both during the initial visit, both in subsequent test, the patients were subjected to the following clinical tests:

a) Physiatric examination, evaluating joint function in order to identify situations of stiffness or ankylosis.

b) Neurological examination.

c) Passive range of motion (pROM) and active (aROM).

d) Assessment of spasticity using the Modified Ashworth scale.

e) Assessment of the properties rheological muscle with Myoton of abductor magnum, medial and lateral gastrocnemius.

f) FIM for children (WeeFIM $®)$.

g) Ultrasound evaluation of muscle target for infiltration with botulinum toxin to exclude the Presence of fibrous tissue, such as muscle metaplasia "do not use".

h) Electromyography evaluation of muscle affected by spasticity.

i) Baropodometric test was performed in order to identify improvements in the following controls about to support of the foot on the ground.

\section{Myometric measure-objective analysis of reologic property muscular}

This method is based on the evaluation of the response of a muscle to a short pulse mechanic, using an instrument called Myometrium, to apply this impulse to the muscle belly. The Myometrium (MYOTON) includes a head positioned by the operator perpendicular to the skin surface that covers the muscle to be investigated; the head gives a gentle pressure, compressing the underlying tissue $[5,6]$. Through an electromagnetic actuator is produced a constant pulse of force for a short period of time. Its duration is of the order of milliseconds. The failure of the electromagnetic actuator causes the head of the device to be quickly released, together with the muscle reacts to impact loading with short damped oscillations. The head is induced to move from these damped oscillations. The performance of the damped oscillations depends on the elastic properties of the muscle tissue. An acceleration transducer record, the oscillations of the head in contact with the skin covering the muscle solicited. The parameters measured by this method are threefold: stiffness, elasticity and frequency.

\section{FIM for children (WeeFIM®)-functional assessment}

Functional assessment in children has been described as "An effort to systematically describe and measure the child's abilities [7] and limitations when performing activities of daily living". Functional assessment is an important component of behavior, because it identifies what the child can do within a specific environment. Many authors have described the advantages of the functional assessment than traditional approaches: the observation of the functional performance allows, even the use of a specific equipment or devices; It is very important for children with physical disabilities and allows observation of the various stages of development; Finally, evaluate the ability to move by walking or using the wheelchair. The purpose of WeeFIM $®$ is to measure the functional changes over time and the impact in terms of physical, technological and financial resources [8]; the rating scale may be calculated through direct observation or administered to caregivers main (parents, teachers) who know the child.

The WeeFIM ${ }^{\circ}$ (Functional Independence Measure for Children, 1993) is an adaptation of the FIM scale normally used to assess disability in adults, in fact, the basic concepts are derived from the definition of disability introduced by WHO in 1980. The WeeFIM $\AA$ measure functional abilities and the need for assistance related to the levels of disbilità in children aged 6 months to 7 years. Items uses the same and the same scoring system FIM classic $[9,10]$. The WeeFIM® is structured to be used with a scale to 7 levels representing more gradations from dependence to independence and then to reflect the need of assistance as a result of disability. It measures the amount of aid provided by another person and necessary for the child with disabilities to reach and maintain an adequate standard of living. In our study we used only two items of the scale WeeFIM, as they are considered more useful to analyze the effectiveness of treatment and the social impact it has on the lives of patients.

\section{Exclusion criteria}

They were excluded from the study patients with the following clinical and social:
a. Scoliosis, demonstrated with RX column.
b. Severe cognitive impairment.
c. Concomitant respiratory problems.
d. Frequent seizures.
e. Musculoskeletal disorders (ankylosis of the hips and knees, tendon retractions).
f. Lack of cooperation of the care-givers. 


\section{Global Journal of Intellectual \& Developmental Disabilities}

g. Minimum compliance by the patient FKT daily and intensive.

The children were subjected to combined treatment with:

i. Botulinum toxin type A(Xeomin $₫$; Merz Pharmaceuticals, Frankfurt/M, Germany). The muscles that we considered were: adductor magnum, medial and lateral gastrocnemius, soleus;

ii. Physiotherapy consisting of stretching the muscles infiltrated, training deambulatory, active and passive mobilizations; proprioceptive excercises, segmental re-education of lower limbs.

The anatomical identification of the muscles to infiltrate was possible using kinesiologycal maneuvers or ultrasound. Analyzed the clinical picture at the initial visit, we evaluated the average time duration of the effect of botulinum toxin [11], the possible improvement of muscle spasticity using the modified Ashworth scale and the nominal change in the rheological properties of the muscles with the myometric measurement. The study was conducted for one year and evaluated times rated were: T0 recruitment and injection, $\mathrm{T} 1=1$ month, $\mathrm{T} 2=3$ months $\mathrm{T} 3=4$ months, T4=5 months, T5 injection $=6$ months $\mathrm{T} 6=7$ months, $\mathrm{t} 7=9$ months, $\mathrm{T} 8=10$ months, $\mathrm{T} 9=11$ months, $\mathrm{T} 10$ injection=12 months).

\section{Analysis of Results}

All clinical variables were subjected to statistical analysis. The test was used t-student for the evaluation of the differences between the averages of the two groups. As regards the muscle tone of the magnum abductors, medial and lateral gastrocnemius, in the group A the statistical analysis showed a significant for $\mathrm{p}<0.05$ to the times $\mathrm{T} 1 \mathrm{p}=0.004, \mathrm{~T} 2 \mathrm{p}=0.005, \mathrm{~T} 3 \mathrm{p}=0.04, \mathrm{~T} 6$ $\mathrm{p}=0.005, \mathrm{~T} 7 \mathrm{p}=0.005, \mathrm{~T} 8 \mathrm{p}=0.03$ (Figure 1); instead, in the group $B$ (Figure 2) the statistical analysis of muscular tone reduction wasn't significant at all times (T1 p=0,64, T2 p=0,89, T3 p=0,49, T6 p=0,30, T7 p=0,085, T8 p=0.88).

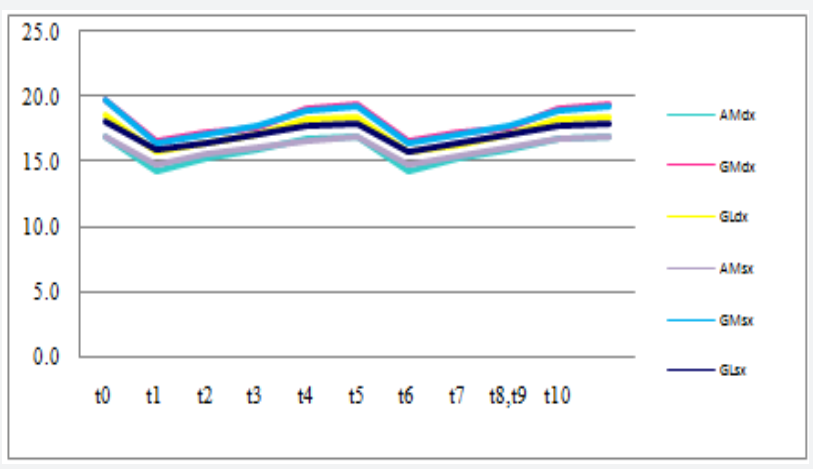

Figure 1: Muscle tone Group A.

We found the same results for the MAS scale in the group A: $\mathrm{T} 1 \mathrm{p}=0.006, \mathrm{~T} 2 \mathrm{p}=0.005$, T3 $\mathrm{p}=0.045$, T6 p=0.004, T7 p=0.005, T8 $p=0.02$ (Figure 3); in the group B we didn't found statistically significant in each times: $\mathrm{T} 1 \mathrm{p}=0,68, \mathrm{~T} 2 \mathrm{p}=0,59, \mathrm{~T} 3 \mathrm{p}=0,44, \mathrm{~T} 6$ $\mathrm{p}=0,31, \mathrm{~T} 7 \mathrm{p}=0,63, \mathrm{~T} 8 \mathrm{p}=0.78$ (Figure 4).

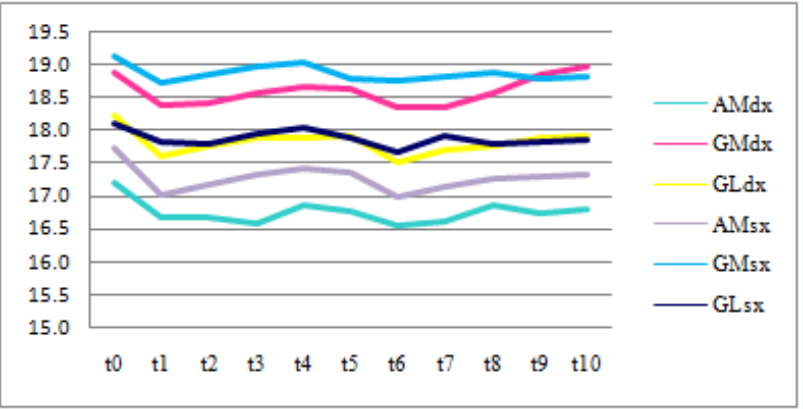

Figure 2: Muscle tone Group B.

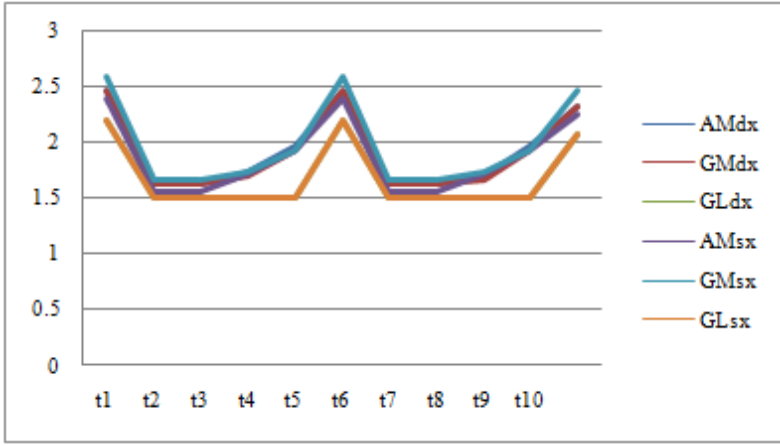

Figure 3: MAS scale Group A.

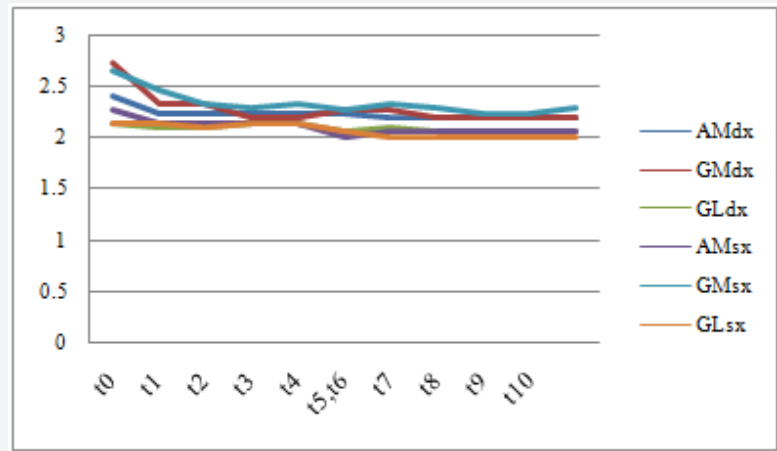

Figure 4: MAS scale Group B.

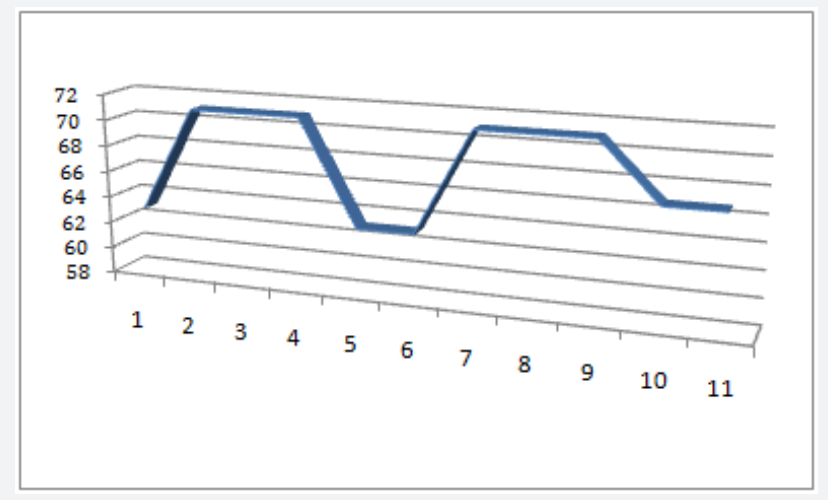

Figure 5: WeeFim Group A. 
Finally, were compared with the test t-student values between the two groups of scale WeeFim: in the group A T1 $\mathrm{p}=0.004, \mathrm{~T} 2 \mathrm{p}=0.003, \mathrm{~T} 3 \mathrm{p}=0.002, \mathrm{~T} 6 \mathrm{p}=0.004, \mathrm{~T} 7 \mathrm{p}=0.003$, T8 $\mathrm{p}=0.02$ (Figure 5); in the group B we didn't found statistically significant in each times: T1 p=0,61, T2 p=0,45, T3 p=0,44, T6 $\mathrm{p}=0,42, \mathrm{~T} 7 \mathrm{p}=0,58, \mathrm{~T} 8 \mathrm{p}=0.67$ (Figure 6).

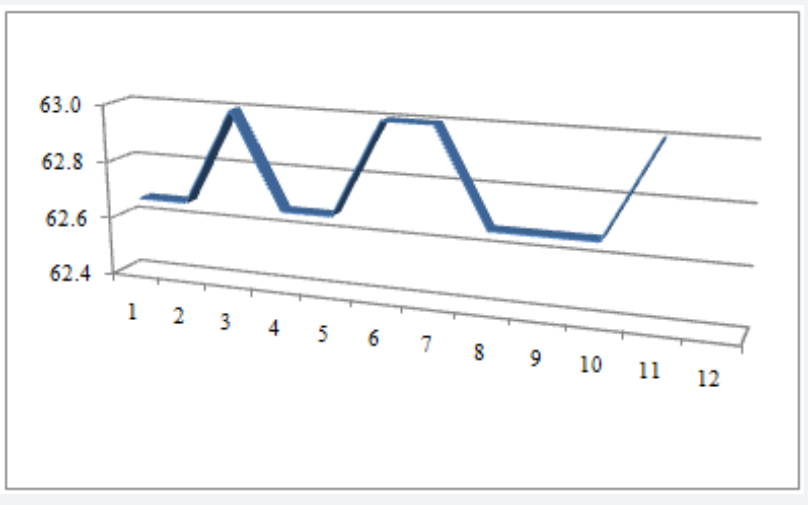

Figure 6: WeeFim Group B.

\section{Discussion}

\section{Effect of the toxin on motor recovery}

One of the goals reached by treatment with botulinum toxin and physiotherapy is to improve the quality and quantity of motor recovery in individuals with cerebral palsy [12,13]. The Modified Ashworth Scale for spasticity assessment is officially recognized for the monitoring of changes in clinical parameters in Cerebral Palsy; so, we can say that the data from this evaluation is to produce evidence of the effectiveness of the treatment to which add in our experience myometric evaluation of changes in the properties of the muscle that validate objectively the results obtained. Enhancements include walking, traveling with a pram, the ascent and descent of stairs, personal care, assistance for dependent patients is less tiring, and increases the time in which the child is able to remain in a sitting position.

Our study showed that the infiltration of specific muscle groups with Botulinum Toxin, is effective in reducing spastic hypertonicity and thus in the reduction of all those symptoms related to this, which result in an impairment of the quality of child's life with outcome of PCI. The marked reduction of muscle tone associated with the use of the toxin allows the rehabilitator to set up a functional treatment targeted and implement the intervention quickly and effectively using, as appropriate, both techniques neuromotor rehabilitation, muscle relaxation, mobilization passive. The rehabilitation treatment following the administration of toxin interrupts the sequence of events that contribute to the anatomical and histopathological change in the passive mechanical properties of the muscle, with a net increase in strength and elastic and plastic remodeling in the sense of tonic muscle spasticity in phase for fiber atrophy II fiber hypertrophy and tonic I. Additionally the ability to mobilize the affected limb spasticity, allows an improvement of vascularization and of trophism of the limb, in fact, the capillary network tends to increase while the amount of connective tissue tends to stabilize, still leads to an improvement of the tone calcic segment skeletal involved. Finally, it results in a recovery of the antagonist muscles , no more unused and deficits, but can be activated and contracts with further remission of spasticity of the agonists. It is desirable continuous monitoring in patients with cerebral palsy $[14,15]$.

\section{Conclusion}

Our observations confirm that the infiltration of Botulinum Toxin in a spastic muscle is a safe and effective treatment for the symptoms of spasticity. The improvements achieved with topical infiltration of toxin, in the context of personal autonomy and reflected in the social life of the patient, allow you to see an improvement in the fundamental tone mood of the disabled, something very important because it promotes a more advantageous motivation the recovery of the patient aiming to achieve complete independence.

The combined action of BTX-A and FKT evaluated with the MAS and Weefim scale and the myometric measurement of muscle tone showed that these patients after combined treatment are able to use motor compartments functional and intentional mode. Thus, this treatment was very important for envelopment the integration of child with cerebral palsy in recreational sports with great social integration and good quality of life.

\section{References}

1. Kent RM (2013) Cerebral palsy. Handb Clin Neurol 110: 443-59.

2. Ocarino JM, Fonseca ST, Silva PL, Goncalves GG, Souza TR, et al. (2013) Dynamic touch is affected in children with cerebral palsy. Hum Mov Sci 33: 85-96

3. Huang CY, Tseng MH, Chen KL, Shieh JY, Lu L (2013) Determinants of school activity performance in children with cerebral palsy: a multidimensional approach using the ICF-CY as a framework. Res Dev Disabil 34(11): 4025-4033.

4. Van Wely L, Balemans AC, Becher JG, Dallmeijer AJ (2013) The effectiveness of a physical activity stimulation program for children with cerebral palsy on social participation, self-perception and quality of life: a randomized controlled trial. Clin Rehabil 28(10): 972-982.

5. Jarocka E, Marusiak J, Kumorek M, Jaskólska A, Jaskólski A (2012) Muscle stiffness at different force levels measured with myotonometric devices". Physiol Meas 33(1): 65-78.

6. Ianieri G, Saggini R, Marvulli RG, Tondi G, Aprile A, et al. (2009) “New approach in the assessment of the tone, elasticity and the muscular resistance: nominal scales vs MYOTON. Int J Immunopathol Pharmacol 22(Suppl 3): 21-24.

7. Sperle PA, Ottenbancher KJ, Braun SL, Lane SJ, Nochajski S (1996) Equivalence Reliability of the Functional Independence Measure for Children (WeeFIM) Administration Methods. Am J Occup Ther 51(1): $35-41$.

8. Braun SI, Granger CV (1991) A practical approach to functional assessment in pediatrics. Occup Ther Practice 2: 46-51.

9. Bar-On L, Molenaers G, Aertbelien E, Van Campenhout A, Feys H, et al. (2015) Spasticity and its contribution to hypertonia in cerebral palsy. Biomed Res Int. 
10. Jost WH, Benecke R, Hauschke D, Jankovic J, Kanovsky O, et al. (2015) "Clinical and pharmacological proprieties of incobotulinumtoxin A and its use in neurological disorders. Drug Des Devel Ther 9: 1913-1926.

11. Strobl W, Theologis T, Brunner R, Kocer S, Viehweger E, et al. (2015) Best clinical practice in botulinum toxin treatment for children with cerebral palsy. Toxins (Basel) 7(5): 1629-1648.

12. Jarocka E, Marusiak J, Kumorek M, Jaskólska A, Jaskólski A, et al. (2012) Muscle stiffness at different force levels measured with myotonometric devices. Physiol Meas 33(1): 65-78.
13. Delgado MR, Tilton A, Russman B, Benavides O, Bonikowski M, et al. (2016) Abobotulinum toxin A for Equinus Foot Deformity in Cerebral Palsy: A Randomized Controlled Trial. Pediatrics.

14. Tilton AH (2015) Evidence-based review of safety and efficacy in cerebral palsy. Toxicon 107(Pt A): 105-108.

15. İçağasıoğlu A, Mesci E, Yumusakhuylu Y, Turgut ST, Murat S (2015) Rehabilitation outcomes in children with cerebral palsy during a 2 year period. J Phys Ther Sci 27(10): 3211-3214.

\section{Your next submission with Juniper Publishers will reach you the below assets}

- Quality Editorial service

- Swift Peer Review

- Reprints availability

- E-prints Service

- Manuscript Podcast for convenient understanding

- Global attainment for your research

- Manuscript accessibility in different formats

( Pdf, E-pub, Full Text, Audio)

- Unceasing customer service

Track the below URL for one-step submission https://juniperpublishers.com/online-submission.php 